\title{
HAND BONE ORTHOSIS MANUFACTURING USING 3D PRINTING TECHNOLOGY
}

\author{
${ }^{*}$ Nabaa Alaa Aldeen 1 \\ Basim Ajel Sadkhan ${ }^{2}$ \\ 1) MSc /Mechanical Engineering Dept., University of Mustansiriyah, Baghdad-Iraq. \\ 2) Asst. Prof Dr. Mechanical Engineering Dept., University of Mustansiriyah, Baghdad-Iraq \\ 3) Prof. Dr. Mechanical Engineering Dept., University of Mustansiriyah, Baghdad-Iraq
}

Bashar Owaid ${ }^{3}$

\begin{abstract}
The aim of the research is to use the technology of three-dimensional printing in the manufacture of a orthotic to treat bone fractures from lightweight thermoplastics instead of using the traditional methods that are made of gypsum material, the practical aspect included taking the measurements of the donor's hand and design of the three-dimensional orthotic- socket in the software (solid work2019), and after that the file was converted to a format (stl) and The g-code file was inserted into the printer software for dividing the 3-D design into slices, and the file into the printer was inserted via (SD card) or via linking the printer with the computer straightforward ,The printer was run, and the file to be printed was selected from the screen set on the printer. The heating process of the nozzle and the bed starts and relies upon the kind of material to be printed, for instant in a material (PLA); the extruder temperature is $\left(210^{\circ} \mathrm{C}\right)$, and the platform temperature is $\left(70^{\circ} \mathrm{C}\right)$. , an ( $\mathrm{f}$-socket) test was performed on it, and the stresses incurred by the predicate were obtained, and the results were acceptable according to standard and laboratory values(110, $150,210,140)$ KPA , we notice the difference between the value of the yielding stress and the ultimate stress of the PLA material ( 41, 34.4) MPA, and this indicates that the PLA is from the ductile materials and is not considered a brittle material .
\end{abstract}

Keywords: $3 D$ printing, orthotic

\section{Introduction}

$3 \mathrm{D}$ printing technology is proceeding with accelerating steps after its first lines were laid in the beginning of the eighties of the last century and the beginning of the nineties was the start of a new era for this technology.The general idea of $3 \mathrm{D}$ printers is that they simulate any threedimensional or three-dimensional shape and create a mirror image of the object and then begin the printing process. Printing operations are carried out after the design of the stereoscope to be printed. Formation is made by means of precise layers of materials used in printing. We obtain an exact replica of the entered design. 3D printing technology is used in many fields, it is used in military applications and the manufacture of many commercial products, and the medical field is considered one of the most important areas that was clearly affected by this technology. With this technique, we were able to print prostheses, arteries and blood vessels and had a great role in orthopedics. Doctors also used this technique to print anthropomorphic image of the fetus so that mothers with blindness, as well as parents, could see their children, It is no longer limited to making things that we mentioned like artificial limbs and others, nor to making models for certain things, but it took another way that

*Corresponding Author: alik81832@gmail.com 
exceeded the limits of what was used before, this way could be the beginning of a real revolution in the manufacture of the drug .

\section{Experimental work}

The steps to manufacture osteopathy are shown in the following

1. The first step is to take the dimensions of the limb to be treated, where in this study the dimensions of the researcher's hand were taken, and then the orthopedics was designed based on these dimensions in the program Solid works 2019, as shown fig. (1)

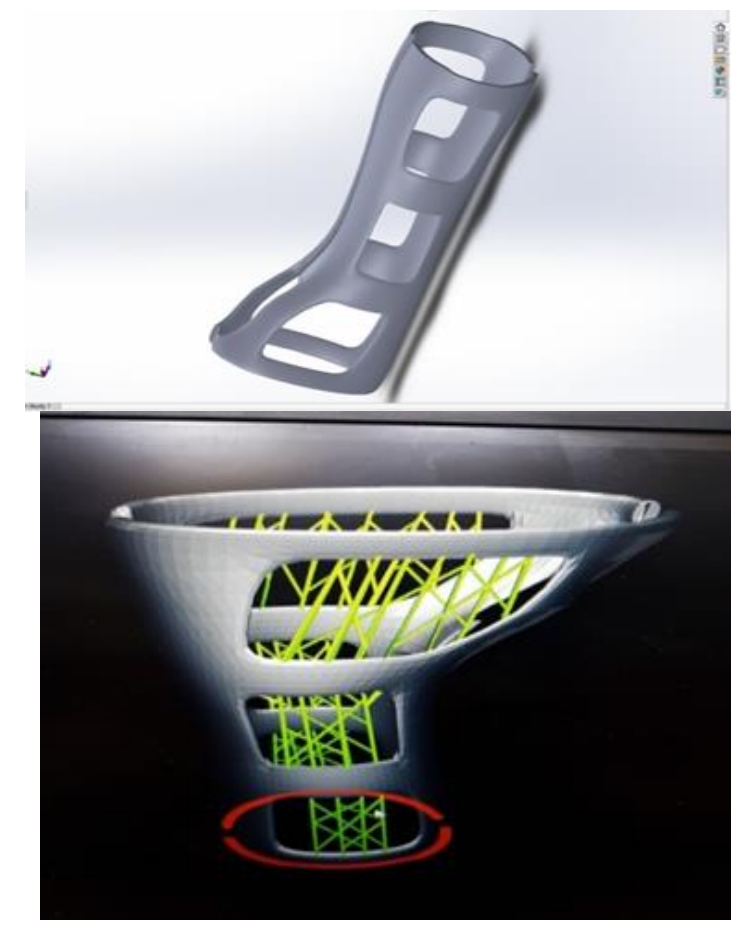

Figure 1. Drawing the orthotic in a software solidwork

2. After designing the orthopedic and converting the file from a format SLDPRT to STL, the file was opened in the computer program for the three-dimensional printer in order to prepare the orthopedist to print in terms of the number of layers composed of it, the number of orthopedic (637), the thickness of each layer, and the temperature of printing. This was determined by the material to be printed where the orthopedic of the material PLA was printed, as well as to know the time taken for the process of printing the ingredient, the time was ( $2 \mathrm{~h}: 24 \mathrm{~m}: 43 \mathrm{~s})$, as shown in below figure.

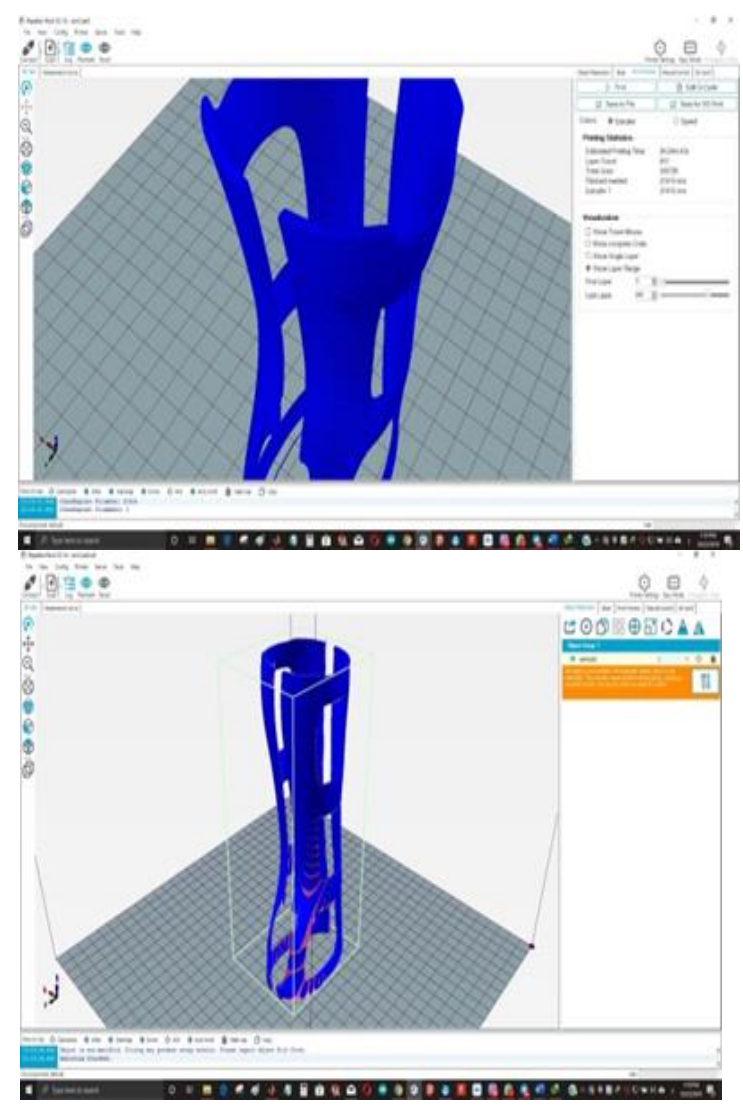

Figure 2. Adjusting the print settings through the printer software

3. The next step was to transfer the file to the printer and the processing of the printer through the process of heating the nozzle and the platform and start the process of printing. The figure below shows the final shape of the predicate. 


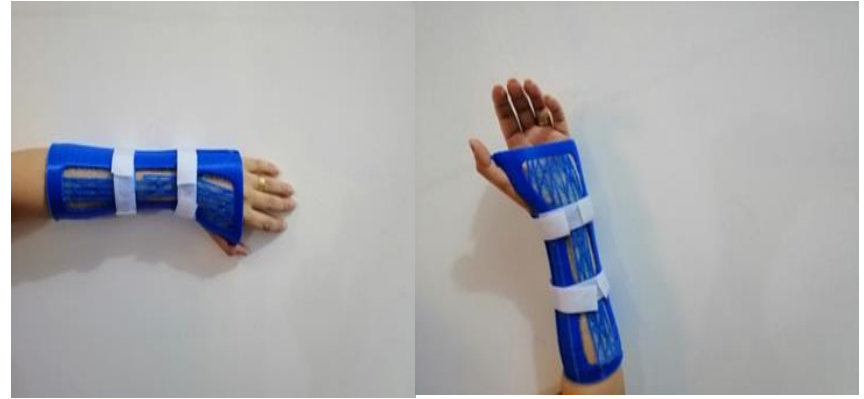

Figure3. The final shape of the orthotic after printing

\section{3. materials in $3 d$ printing}

Thermoplastics are used in 3D printing in the FDM because they are capable to shift in position in a governed way and then become solid. Also, they have a variety of characteristics, such as hardness, flexibility, in addition to these properties owned by the Thermoplastics. Printing in the FDM has some characteristics that make it possess ideal ranges for the purpose of production [1]. These properties have a coefficient of decrease in thermal expansion, which helps reduce the internal stresses resulted by the cooling process as well as keeping the last component nearer to the initial three-dimensional model. The low (TG) will mean that the component softens sooner after heating if the material has a low melting temperature, it is easier to print [2 ]. Below are some of the filaments commonly used for FDM [3]

1. Poly lactic acid (PLA) plastic

2. Acrylonitrile Butadiene Styrene (ABS) plastic

3. High-Impact Polystyrene (HIPS) plastic

4. Thermoplastic Polyurethane (TPU) elastomer

5. Polyethylene Terephthalate (PET) plastic

6. Nylon

7. Composite Printing Filament - Plastic Matrix Fills Polycarbonate.

The following material are used in manufacturing the orthotic:

\subsection{Poly lactic acid (PLA) filament :}

PLA is one of the most common materials in FDM 3D printing. It is environmentally friendly because it is produced from renewable sources such as maize, it is a biodegradable material [4]. Some PLA types are used in medical implants that decompose into the human body. Over time, no damage is created and replaced with a growing tissue [5]. The most important advantages of PLA used in FDM printers are that they do not emit gases that are toxic during melting and are able therefore for printing without a system of ventilation [6].figure (4) show the filament of pla.

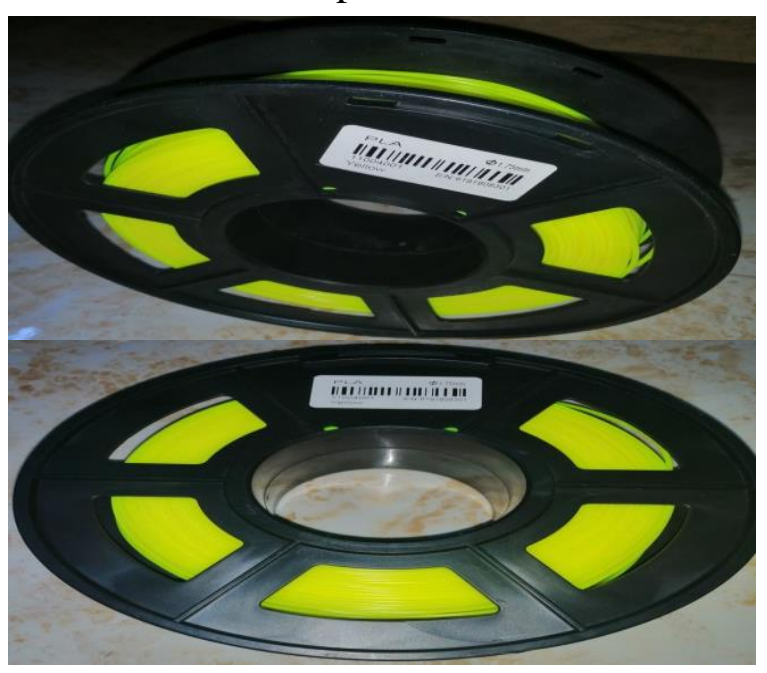

Figure 4. PLA filament

\subsection{Physical properties of PLA}

The temperature of the low glass transmission is where most PLA compounds have a (TG) of 60$65^{\circ} \mathrm{C}$, where suddenly the substance loses the hardness but doesn't vary its phases yet. Therefore, the material is not exposed to a lot of internal stresses during the cooling process. The PLA dissolves at $175^{\circ} \mathrm{C}$, but it is released and flung through the nucleus at $215^{\circ} \mathrm{C}$ [7]. This material enjoys greater fragility as well as high surface hardness, which can be cut, cooled, polished and sanded. And, adhesives with each 
other, when using adhesives, cannot be treated with these materials using Aston [8] .

\section{Engineering Tests}

\subsection{Tensile test}

For the purpose to recognize the mechanical properties of the substance, a tensile test ought to be conducted, so the tensile testing was performed for studying the mechanical properties of three-dimensional printed substances. Such test was done in according to (ASTMD638) standards (fig.5). The next diagram depicts the sample design and dimensions in accordance with such measurements. The Young's modulus (E), yield strength ( $\sigma \mathrm{y})$, tensile strength (UTS), were obtained using the (TINIUS OLSEN) machine, Fig. 6 The tensile specimens for PLA.

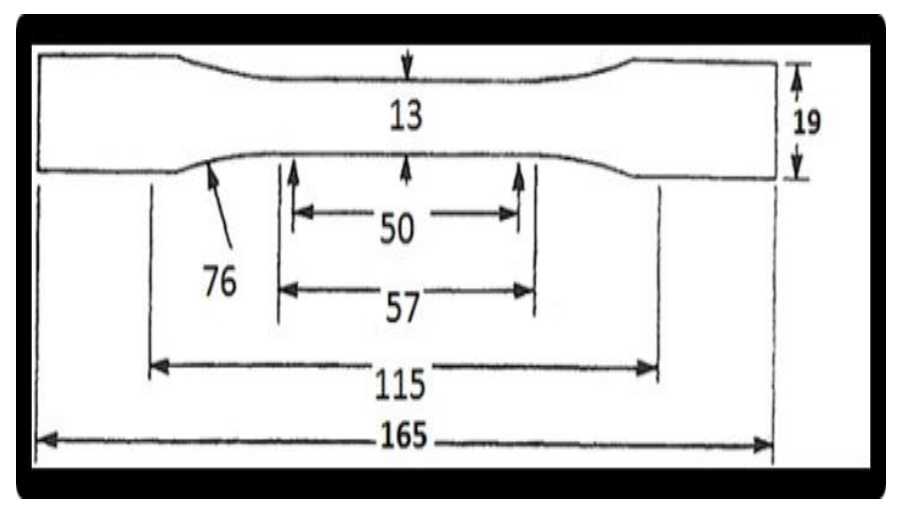

Figure 5. The tensile test specimen according to the standard ASTM D-638 type I [9]

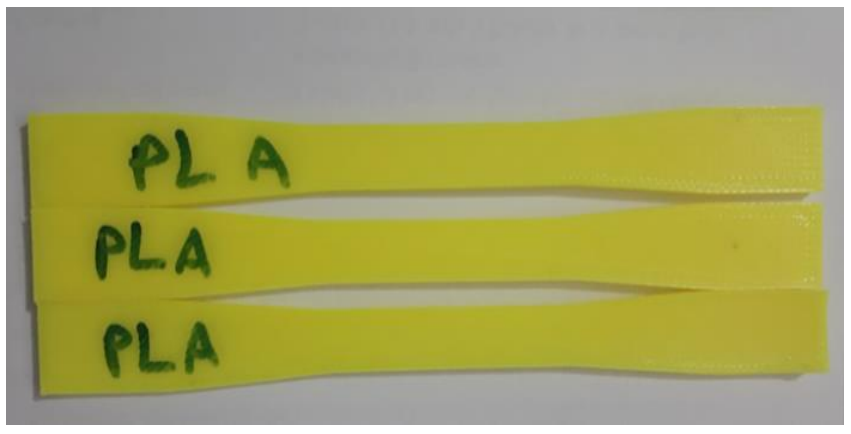

Figure 6. The tensile specimens for PLA.

\subsection{F-socket Testing}

In this study, the interface pressure between the orthotic and the broken limb was measured by the F-Scan pressure measurement system sensors that consist of sensors, as shown in the plate (1) and it was carried out in the Prosthetic and Orthotic Department/Al-Nahrain University. The test was done on a patient who was (25) years old with a broken hand, as elucidated in the plate (1). The sensors were placed on the broken limb covering the anterior of the limb, and then the socket was put on, the patient started to move, as manifested in the plate (1). The device was started to record this movement, and then the placement of F-socket on the poster or, lateral and medial part of limb was repeated. During the movement of patient, the software started to record the movement and draw a curve between the pressure and time. 


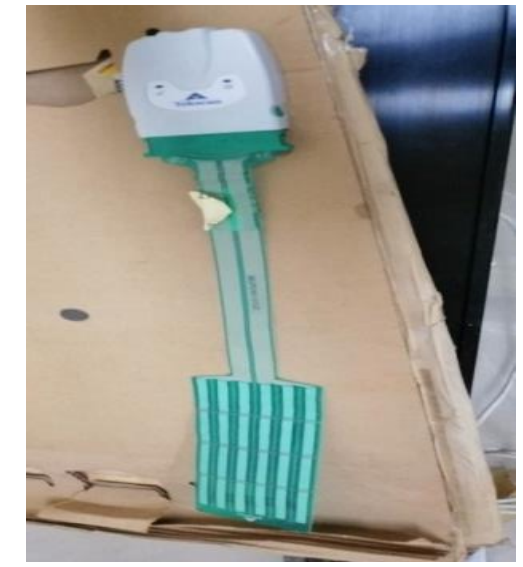

(a)

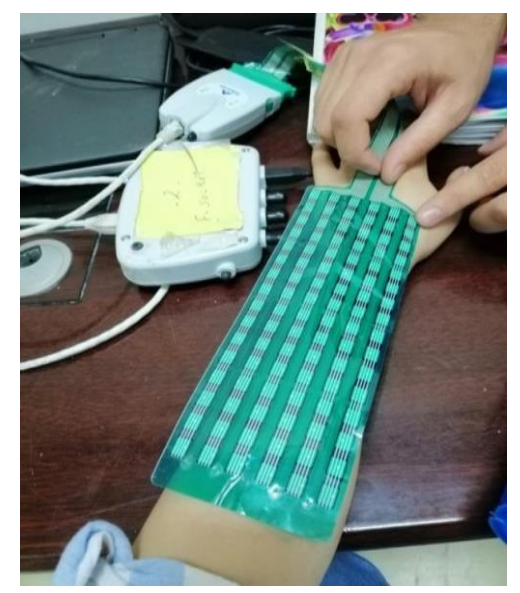

(b)

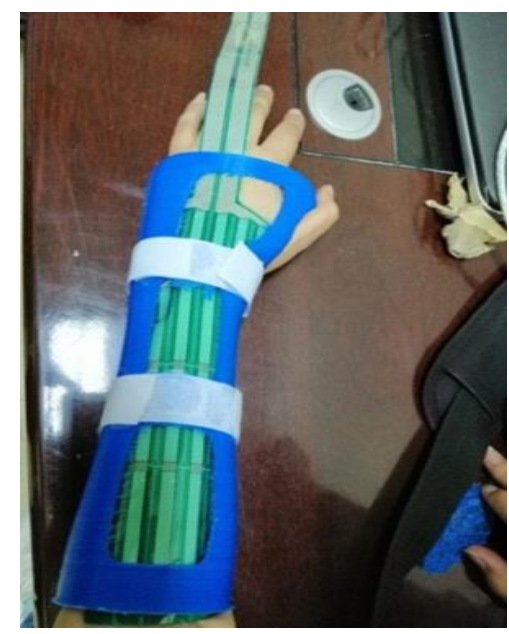

(c)

Figure 7. a) F-Socket sensor model 9811E b) Place the sensor at the hand of the donor c) Put the sensor on the inner area of the

\section{Results and Discussion}

\subsection{Tensile test}

The properties of pla material (Young's modulus, yield stress and ultimate tensile stress) resulted from the tensile test are shown Table 1.

Table 1. The Properties of PLA.

\begin{tabular}{|c|c|c|c|c|}
\hline Material & $\begin{array}{r}\operatorname{load}_{\max } \\
(\mathrm{KN})\end{array}$ & $\begin{array}{l}\sigma_{\text {ult }} \\
(\mathrm{MPa})\end{array}$ & $\sigma_{\mathrm{y}}(\mathrm{MPa})$ & $\mathrm{E}(\mathrm{MPa})$ \\
\hline PLA & 1.616 & 39 & 33 & 1106.20 \\
\hline PLA & 1.762 & 42 & 36 & 1021.91 \\
\hline PLA & 1.788 & 43 & 35 & 1116.23 \\
\hline PLA & 1.660 & 40 & 37 & 1062.46 \\
\hline PLA & 1.718 & 41 & 31 & 1129.28 \\
\hline
\end{tabular}

Through the figure below, we notice the difference between the value of the average the yielding stress and the ultimate stress of the PLA material (41, 34.4) MPA , and this indicates that the PLA is from the ductile materials and is not considered a brittle material because it is going through the stage of plasticity or permanent deformation before it reaches the stage of failure and this characteristic is important in the artificial limbs and supports To achieve the desired comfort and its suitability with the required shape, As for the value the average of the modulus of elasticity (1087.21 MPA ) according to the standard values of thermoplastics it is considered a high value. Therefore, the PLA material is considered to be elasticity and resistance to tensile strength at the same time. Because the increase in the modulus of elasticity is caused by the increase in the stress applied with increased strain. 


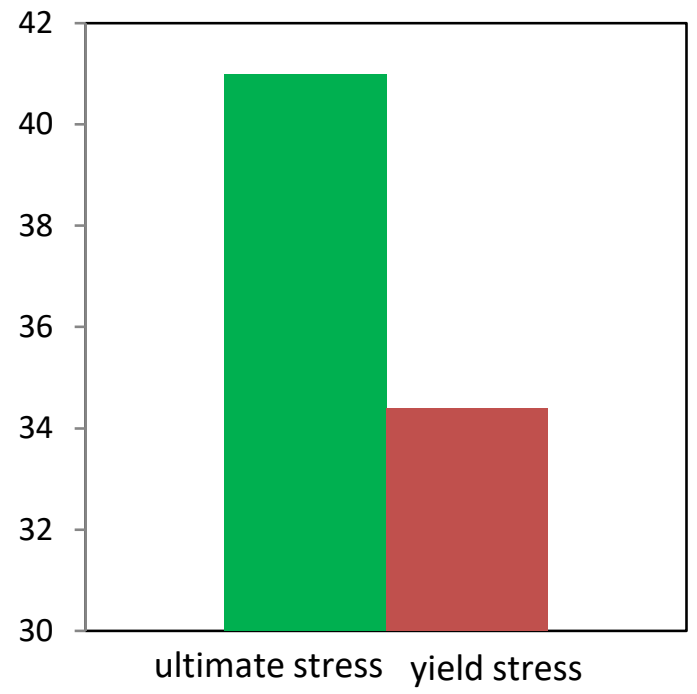

Figure 8.mechanical properties for PLA

\subsection{Interface pressure result between the broken} limb and orthotic

The socket interface designs can be divided into four basic categories according to their respective weight bearing characteristics (anterior posterior, lateral and medial). The interface pressures between the broken limb and the socket were recorded as the participant's movements, such as carrying the bag, opening the door, pushing the chair, and holding the pen. These are called daily activities to analyze the system of motion of patient; the exerted pressure results of the case study from the F-socket software are demonstrated in fig 6 to 9. The location and the maximum pressure values of the hand move generated in the socket are given in Table 2.

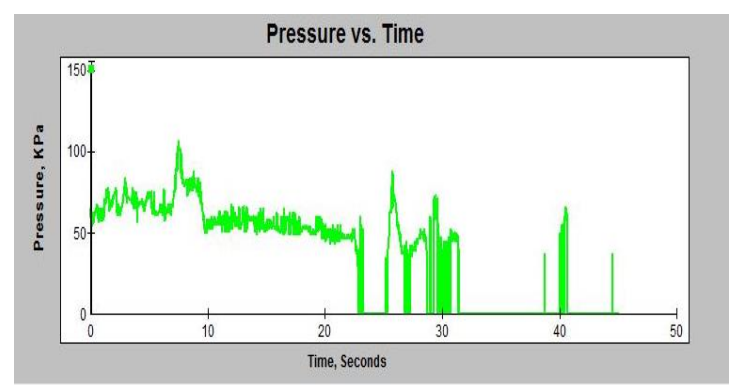

Figure 9. Pressure result at anterior part

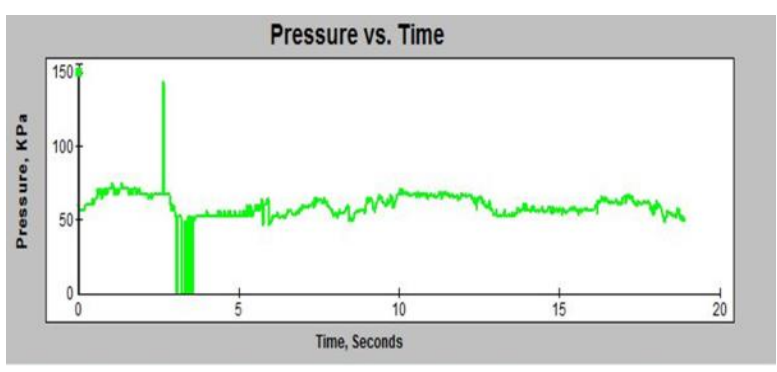

Figure 10. Pressure results at posterior part

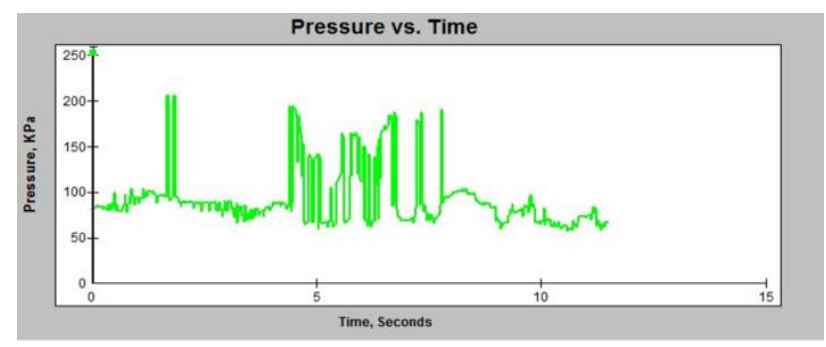

Figure 11. Pressure result at lateral part

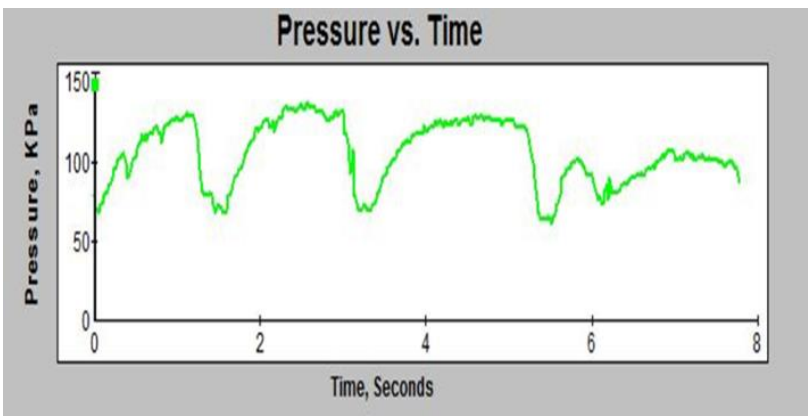

Figure 12. Pressure results at medial part

Table 2. Location and maximum pressure values of the hand move generated in the orthotic

\begin{tabular}{|c|c|}
\hline Location & $\begin{array}{c}\text { Maximum pressure value } \\
(\mathrm{kPa})\end{array}$ \\
\hline Anterior & 110 \\
\hline Posterior & 150 \\
\hline lateral & 210 \\
\hline medial & 140 \\
\hline
\end{tabular}




\section{Conclusions}

1. Through the results of the tests, we conclude that the three-dimensional printing technology can replace traditional manufacturing methods in some industrial, medical, agricultural, military and other fields. This technique has proven the speed in printing samples and reaching their final form for several hours only compared to the casting process that takes days. To obtain the final shape, as well as the ultimate precision in printing, and finally it was revealed through the tensile test that the threedimensional printing materials possess good mechanical properties that enable them to face external conditions.

2. As for the f-socket test conducted on the orthotic through the pressure that we obtained, it is concluded that the orthotic made with 3D printing technology is successful in bearing the pressure on it to treat bone fractures.

3. The orthotic made in the 3D printer is much better than the orthotic made with traditional methods, as it has many advantages, including the accurate design on the patient's hand, light weight, and comfort while wearing because it contains holes that make the patient able to shower and expose the affected party to sunlight and the open air .

\section{Acknowledgements}

The author would like to acknowledge: (AlMustansiriyah University - mechanical engineering dep. Labs),(Baghdad Artificial Limb Center),(Al-Nahrain University_ Engineering college_ Department of prosthetic and orthotic)Baghdad -Iraq for the provision of facilities.

\section{Conflict of interest}

There are not conflicts to declare
Abbreviations
- 3d three-dimension
- FDM fused deposing modeling
- PLA poly lactic acid
- E modulus of elasticity
- $\sigma y \quad$ yield stress
- $\sigma \mathrm{u} \quad$ ultimate stress

\section{Reference}

1. Snyder TJ, Andrews M, Weislogel M, Moeck $\mathrm{P}$, StoneSundberg J, Birkes D, Friedman S (2014) 3D systems' technology overview and new applications in manufacturing engineering science and education. 3D Print Addit Manuf 1(3):169-176.

2. Makerbot FAQ. http://www.makerbot.com/faq./

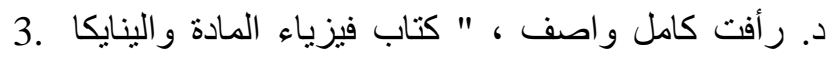

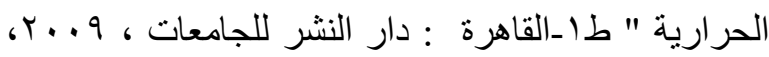

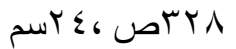

4. Hartmann MH (1998) In: Kaplan DL (ed) Biopolymers from renewable resources. Springer, Berlin, Germany, pp 367-411.

5. F. Rengier $-A$. Mehndiratta $\bullet$ H. von TenggKobligk ,C. M. Zechmann • R. Unterhinninghofen ,H.-U. Kauczor • F. L. Giesel ," 3D printing based on imaging data: review of medical applications ", Int J CARS (2010) 5:335-341.

6. Bellini A, Güçeri S. Mechanical characterization of parts fabricated using fused deposition modeling. Rapid Prototyping ,Journal 2003 Vol 9(4), Pages 252-264.

7. Turner NB, Strong R, Gold SA (2014) A review of melt extrusion additive manufacturing processes: I. Process design 
and modeling. Rapid Prototyp J 20(3):192204 .

8. Kyoung-SU Seol, Panxi Zhao, Byoung-Chul Shin, Sung-Uk Zhang, " Infill Print Parameters for Mechanical Properties of 3D Printed PLA Parts " Journal of the Korean Society of Manufacturing Process Engineers, Vol. 17, No. 4, pp.9-16(2018.08) ISSN 22880771 .

9. Standard Test Method for Tensile Properties of Plastics D638, This standard has been approved for use by agencies of the U.S. Department of Defense. 